\title{
Method of determination of survival characteristics of weapons and military equipment
}

\section{Volodymyr Dachkovskyi ${ }^{A}$}

Received: January 20, 2020 | Revised: February 20, 2020 | Accepted: February 29, 2020

DOI: $10.33445 /$ sds.2020.10.1.3

\begin{abstract}
In order to repel armed aggression in the East of Ukraine, the national defense-industrial complex has modernized and developed a significant nomenclature of weapons and military equipment, which correspond to the forms and methods of conducting modern hostilities. Experience of using the samples of weapons and military equipment, which are allowed to exploitation in the Armed Forces of Ukraine, indicates on the necessity of resolving a number of problematic issues related to tecnical maintenance, repair, providing of logistical means etc., for keeping them in working order

Keeping the samples of weapons and military equipment in working order in conditions of fightfare is determined by the number of factors, the one of which is their survivability, namely ability of sample of weapons and military equipment to keep their parameters in given limits, withstand damage of all kinds, and in the event of damage retain the possibility of combat use after repair with minimal cost of time and repair.

The article proposes a technique for determining the survivability characteristics of a sample of weapons and military equipment. This technique makes it possible to determine the durability and reproducibility indices of weapons and military equipment samples thereby determining the survivability of a particular weapons and military equipment sample or group of single-purpose machines.
\end{abstract}

Keywords: weapons and military equipment, survivability, stability, reproducibility.

\section{Introduction}

\subsection{Novelty of the research}

The experience gained by units of the Armed Forces of Ukraine in the anti-terrorist operation (ATO)(operations of the United forces (OUF)) during the combat missions in the Donetsk and Lugansk regions has shown that the aggressor to gain an advantage widely uses both the latest (modernized) and the advanced already wellknown (from the experience of the armed conflicts of the late twentieth - early twentyfirst centuries) samples of weapons and military equipment (WME). The intensive use of enemy artillery and the increase in the intensity of use of mine-explosive means lead to an increase in losses, both in personnel and in the weapons and military equipment.
Since the beginning of the ATO (OUF), a wide nomenclature of weapons and military equipment samples has been admitted to operation in the Armed Forces of Ukraine. However, an analysis of the damage received by the weapons and military equipment samples, which have been upgraded or re-manufactured, indicates that the units of the ground troops had to face a number of problems related to maintaining the weapons and military equipment in working order. That is, samples of weapons and military equipment used by the units in the course of the task often lost their working condition for the restoration of which was spent additional material resources (ATR), financial costs, etc. In addition, the time of

\footnotetext{
A National Defence University of Ukraine, Associate Professor of Technical Support Department, Candidate of technical sciences (Ph.D.), Associate Professor of Technical Support Department, 28, Povitroflotsky, ave, Kyiv, 03049, Ukraine, e-mail: 1903vova@ukr.net, ORCID: 0000-0003-1480-5021
} 
incapacitated samples of weapons and military equipment under repair was $60 \%$ higher than the normative indexes [1]. All this is due to the low level of survivability of these weapons and military equipment samples compared to the means of their defeat, which confirms the relevance of this study.

\subsection{Analysis of recent research and publications}

A number of studies have been devoted to the study of the survivability of weapons and military equipment in the course of the tasks on purpose, in particular, in the work [2] an analysis of existing and prospective coatings for enhancing the survivability of weapons and military equipment on the battlefield was carried out . In the work [3] the nature and content of an alternative approach to the empirical assessment of the survivability of vehicle samples and armored combat vehicles are revealed. This approach is based on the expert evaluation of the protection of vehicles and armored combat vehicles against the means of detection and damage of the enemy.

Thus, in the work [4] the methodological bases of estimation and prediction of the quality and efficiency level of the purpose of the weapons and military equipment samples are considered, and in the work [5] the increase of the survivability of the sample of weapons and military equipment is considered due to the decrease of the thermal radiation that occurs in the tires which are constantly subjected to loading and deformation. In the work [6] approaches to increasing the survivability of weapons and military equipment are presented, and in [7] an analysis of military equipment failures and views on ways to improve the existing weapons and military equipment maintenance and repair system are presented. The literature sources [8] present the results of losses of combat vehicles from various means of destruction and consider ways to improve their security, and in the work [9] is considered the method of estimation of the technical level of samples of the weapons and military equipment which is based on the comparative analysis of the tactical and technical characteristics of the samples and the use of the group method peer review. In the work [10] the concepts of reliability and survivability of complex systems are considered, the expediency of using survivability analysis methods for estimation of topological structures of complex military systems and rational spatial placement of their elements is shown, and in the work [11] the variant of formation of information support system for estimation of the level of reliability of weapons and military equipment in the implementation of the maintenance and repair strategy is considered. In the work [12] presents an approach to the problem of improving the maintainability ofweapons and military equipment as one of the ways of improving the efficiency of functioning of weapons and military equipment in the conditions of combat training of troops.

\section{Material and Method}

The purpose of the article is to disclose the nature and content of the technique for determining the characteristics for assessing the survivability of weapons and military equipment samples during combat operations, which may form the basis for designing new or upgrading existing weapons and military equipment samples.

\section{Results and discussion}

The experience of conducting military operations indicates that in many cases there is a need to assess the survivability of weapons and military equipment samples. This need usually arises in the development of new samples of weapons and military equipment and the upgrading of existing ones in order to improve their combat or operational capabilities. The need for assessing the survivability of weapons and military equipment samples may also arise when planning the maintenance of troops, the creation of MTZ reserves, etc. 
To date, the evaluation of the survivability of weapons and military equipment samples is carried out by comparing different variants of structures with the main indicators of tactical and technical characteristics $[3,10]$. This method of assessing the survivability of weapons and military equipment samples cannot be considered rational for a number of reasons, namely:

it allows to compare only the numerical indicators of the tactical and technical characteristics of the samples, where there are no survivability indicators;

the criterion for assessing survivability is quite often subjective, since survivability is not assessed directly or indirectly through intermediate indicators.

The absence of uniform indicators of survivability of weapons and military equipment samples and a systematic evaluation methodology makes it impossible to estimate the survivability of a particular weapons and military equipment sample or the comparative survivability of a singlepurpose weapons and military equipment sample group This greatly complicates the work of designers, manufacturers, operators and repairers. This problem can be solved with the advent of the basic quantitative characteristics of survivability and the parameters of their evaluation.

You can solve this problem by using specific indicators that would be express the quantitative value of the survivability components, as well as correlate these indicators with each other.

Before presenting the rationale for the methodology for constructing specific survivability characteristics that correlate the main indicators, it is necessary to briefly consider the relationship between tactical and technical requirements for the survivability of weapons and military equipment samples.

When developing and upgrading weapons and military equipment samples, sustainability and especially reproducibility issues are considered to be minor compared to tactical and technical requirements. This leads to heavy material costs for repairs and a reduction in the combat potential of the troops. Nowadays, in connection with the admission of more sophisticated weapons and military equipment samples to the armies, more attention should be given to these issues, both during the development and during the modernization of the weapons and military equipment samples.

Currently, the development of weapons and military equipment samples has been focused on meeting the tactical and technical requirements. This was due primarily to the fact that the tactical and technical requirements are clear: they can be set and measured, they can be calculated, and subsequently checked during the pilot tests. Therefore, meeting the tactical and technical requirements is of great importance. It is only natural that all other issues related to the possibility of destruction of the sample of the weapons and military equipment, its further restoration, were relegated to the background, since they could not be expressed by values that could be measured or calculated.

Given that it is now possible to really evaluate such parameters as the resistance to the impact factors of different lesions [13], the reproducibility [14], etc., then these issues when designing and upgrading weapons and military equipment samples should be addressed on a same level with tactical and technical requirements. A possible variant of the components of the task for the development of the sample of weapons and military equipment is shown in Fig. 1 . As can be seen from the scheme, the tactical and technical requirements include a constituent of the requirements of the survivability of the sample weapons and military equipment. The aggregate of these components determines the combat effectiveness of an weapons and military equipment sample that is being developed or upgraded.

Considering the components of the scheme, we can conclude that the technical and tactical requirements and limitations can be easily analyzed, as they are usually set by digital indicators [15]. Somewhat more difficult with the components of survivability. However, survivability components can be expressed through appropriate indicators. 


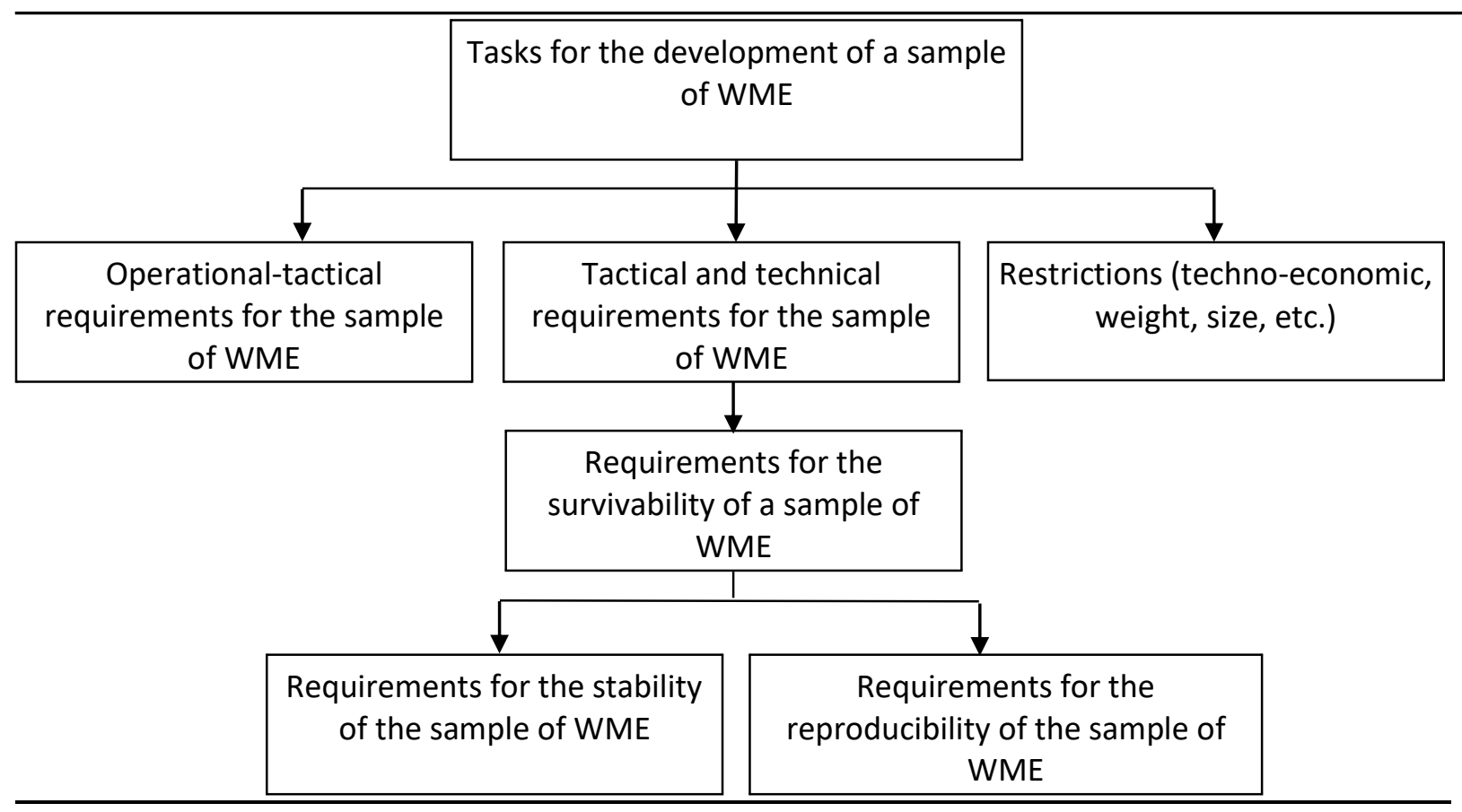

Fig. 1 Flowchart of the task of developing a sample of weapons and military equipment

Such indicators may be the vulnerability of the weapons and military equipment sample, which is expressed by the likelihood of the sample of the weapons and military equipment failing when it is hit by the lesion means $B_{\mathrm{j}}$ or by the stability factor of the weapons and military equipment sample $K_{\mathrm{cm}}$. Reproducibility can be expressed by the basic criterion of evaluation - the downtime of the sample of the weapons and military equipment in repair $T_{\mathrm{p}}$ or by the coefficient of reproducibility of the weapons and military equipment sample $K_{\mathrm{b}}$ [15]. These values are real numbers and can serve as a parameter for the developed or upgraded weapons and military equipment samples, as well as the estimation parameter for the in-service serial weapons and military equipment samples. Value $B_{\mathrm{j}}$ - is the probability of a sample of the weapons and military equipment failing for any particular $j$ - reason, when hitting by the defeat means in the sample weapons and military equipment may take quite certain values, since it expresses the ratio of the projection area of the sample weapons and military equipment, hit by one means of damage puts the sample weapons and military equipment out of order $j$ - this reason, to the entire area of the projection of the sample weapons and military equipment on the scattering plane.

Vulnerability of an weapons and military equipment sample can also be carried out using the coefficient of stability of the sample of the weapons and military equipment. For this purpose, you need to determine two indicators: the average required number of hits $\omega$ and the probability of a given number of $m$ hits of $n$ shots.

The ratio of the average required number of hits to the total possible number of hits will characterize the magnitude of the resistance factor of the sample weapons and military equipment to the striking factors of this type of weapon. The higher the coefficient of stability, the lower the vulnerability of an weapons and military equipment sample, which is analyzed for the striking factors of a given weapon.

Similarly, the possibility of repairing a damaged weapons and military equipment sample can be assessed. For this purpose it is only necessary to determine the coefficient of reproducibility of the sample weapons and military equipment. The higher the recovery rate, the higher the probability of recovery in the event of damage.

The possibility of restoration of a sample of weapons and military equipment can also be 
assessed using the basic criterion for assessing the recoverability - the time of finding the sample of weapons and military equipment in repair. The shorter the time of finding a sample of weapons and military equipment in repair, the higher its recoverability.

Thus, the sustainability and reproducibility of an weapons and military equipment sample that is being developed or upgraded can be design parameters and given certain values that can be realistically measured or calculated. These indicators are important because the viability of the weapons and military equipment sample can be assessed when designing or upgrading an weapons and military equipment sample. Such a technique is necessary at the initial design stage, where it is important to quantify the correctness of the design decisions made.

It should be noted that the existence of a systematic methodology for assessing the survivability of weapons and military equipment samples will greatly contribute to the work of the organizers of the technical support of the troops. To date, the basic baseline data for technical planning are based on past wars and various exercises.

In a number of cases, these data do not give a realistic idea of either the magnitude of the losses or the nature of the damage to the weapons and military equipment samples. Therefore, determining the sustainability and reproducibility of weapons and military equipment samples is one of the main tasks in predicting a likely repair fund. It is likely that the above parameters for assessing the stability and reproducibility of weapons and military equipment samples can be used to evaluate the viability of an weapons and military equipment sample.

In a number of cases, a single criterion for assessing the survivability of an weapons and military equipment sample may be required, that is, a criterion that covers both the stability and reproducibility of the weapons and military equipment sample being analyzed.

Defining a single criterion for the survivability of an weapons and military equipment sample is quite a challenge. This is explained by the fact that each of the constituents of survivability has a different degree of influence on the survivability of the sample of the weapons and military equipment being analyzed. Therefore, in practice, it is necessary to develop a generalized indicator that would take into account the degree of influence of each of the components on the level of survivability of the sample weapons and military equipment. This may be an indicator that takes into account the relationship between the likelihood of an weapons and military equipment sample failing combat damage and the likelihood of its recovery in the event of damage.

It is known that the likelihood of an weapons and military equipment sample failure is determined by its resistance to the impact factors of the various lesions, and the probability of recovery by its reproducibility. The robustness of an weapons and military equipment sample to the striking factors of various lesions can be characterized by a number of quantitative characteristics, the most important of which is their affection [16]. It determines the likelihood of finding an weapons and military equipment sample in a serviceable state during combat operations. Similarly, this reproducibility can also be characterized by a number of quantitative characteristics, the most important of which is the length of time a sample of weapons and military equipment is in repair.

If we denote by $W_{\mathrm{b}}$ the criterion for evaluating the finding of the weapons and military equipment sample in a viable state during combat operations, and through the $K_{\mathrm{b}}$ criterion for evaluating the renewal of the weapons and military equipment sample in cases of its defeat, then the general criterion for assessing the survivability of the weapons and military equipment sample can be obtained from the relation [17].

$$
Z=\frac{K_{s}^{2} W_{s}}{1+\left(\begin{array}{ll}
K_{s}^{2} & 1
\end{array}\right) W_{6}}
$$

Analyzing this equation, we can conclude that the quantitative value of the criterion of survivability of the sample weapons and military equipment can be calculated depending on the main indicators that characterize, on the one hand, the probability of damage to the sample weapons and military equipment, on the other the probability of its recovery in cases of damage. 
In other words, the likelihood of finding the weapons and military equipment sample in a functional state during combat operations may be characterized by its resilience, and the likelihood of recovery in the event of damage by an indicator of recoverability.

In the work [4] it was noted that with the increase of stability and reproducibility indices of weapons and military equipment samples, their survivability sharply increased. At the same time, the predominant influence on the growth of survivability gives an indicator of the stability of the sample weapons and military equipment to the striking factors of various means of struggle.

In some cases, dependencies of the survivability index change may be required to determine the survivability indices of weapons and military equipment samples, with constant changes in the indices of its constituents. This dependence can be obtained using equation (1). This equation can be considered as a surface equation in coordinates $Z, K_{\mathrm{b}}, W_{\mathrm{b}}$. The survivability value in this equation is represented in a differential form, that is, it gives an idea of the survivability of the weapons and military equipment sample in probabilistic form only with unambiguous values of the constituents $\Delta K_{\mathrm{b}}$ and $\Delta W_{\mathrm{b}}$

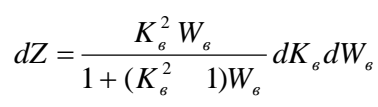

However, for probability calculations, this equation is not always acceptable, since in a number of cases knowledge of the general probabilistic character of survivability of an weapons and military equipment sample, which is investigated by changing the constituent values $K_{\mathrm{b}}$ and $W_{\mathrm{b}}$ from zero to the specified level.

In this case, equation (2), presented in the differential form will not satisfy us. Obviously, in this case, the equation must be presented in an integral form. Such an integral characterizing the volume placed between the coordinate planes that corresponding to a given value $K_{\mathrm{b}}$ and $W_{\mathrm{b}}$, as well as the surface $Z$, will determine the value of the probability of survivability.

The difficulty of obtaining an integral expression of survivability is that the survivability index $Z$ is a function of two variables $K_{\mathrm{b}}$ and $W_{\mathrm{b}}$, which vary simultaneously from 0 to 1 . However, such integration is quite possible. In the general form, the equation can be represented as

$$
P_{z}=\int_{0}^{K_{s}} d K_{\theta} \int_{0}^{W_{s}} \frac{K_{s}^{2} W_{s}}{1+\left(K_{\theta}^{2} 1\right) W_{s}} d W_{\theta}
$$

Conducting a sequential transformation $d W_{6}$ we get

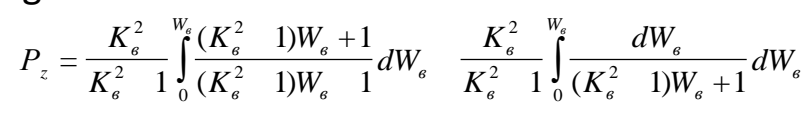

Similarly, conducting the transformations we get

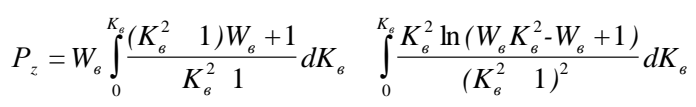

The final transformations give the final equation

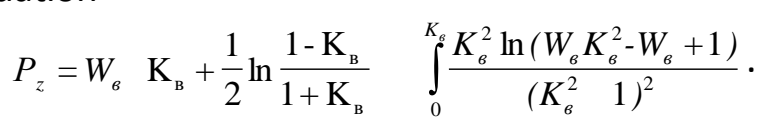

\section{Conclusions}

Thus, the determination of the quantitative value of the criterion of survivability of weapons and military equipment samples makes it possible to determine the survivability of a specific sample of weapons and military equipment or a group of machines of one purpose, and therefore to compare them with each other.

In the future, it is advisable to analyze the design of existing samples of weapons and military equipment and those that are being developed to obtain estimates of their sustainability and reproducibility.

\section{References}

1. Matsko O. Y., Tereshchenko AM, Kopashynskyi S.A, Ovcharenko I.V, Dachkovskyi V.O, Yalnytskyi O.D, Openko P.V, Yaroshenko O.V, Momot R.A., Grinchak O.V.
Fundamentals of Organization of Operation and Repair of Weapons and Military Equipment, Kyiv, NUOU, 2018, 400 p. 
2. Bachynskyi, V.V. Khyzhnyak, Zh.O. Sheleyko, O.S. Possibilities of special coatings for increasing the survivability of weapons and military equipment Collection of scientific works of the Military Academy (Odessa). 2015. Vol. 1, p. 5-10.

3. Sivak V.A. An alternative approach to assessing the survivability of vehicle samples and armored combat vehicles. Weapons and military equipment. 2016, No. 3 (11), p. 30-34

4. Demidov, B.A. Khmelevskaya, O.A. Methodical bases of estimation and prediction of quality level, comparative analysis of efficiency of application of samples of armaments and military equipment in the management of their life cycles. Radioelectronic and Computer Systems, 2006, №7 (19, p.) 72-76.

5. Babakin, A.N. Enhancing the honor of military automotive technology through the use of modern, cost-effective car tires. Proceedings of the International Scientific and Technical Conference of Automobile and Tractor Engineering in Russia: Priorities for the Development and Training of Personnel, dedicated to the 145th anniversary of MGTU "MAMI" Moscow. with. 22-28

6. Dachkovskyi, V.O. Ovcharenko I.V, Baghdasaryan N.K., Yaroshenko O.V. Directory of the officer of the reconstructed military unit (unit) on the renewal of weapons and military equipment. Kyiv, NUOU, 2016, $79 \mathrm{p}$.

7. Gulyaev, A.V. Zubarev, O.V. Kanishchev, V.V. Kolodyazhnyi, V.B. Improving the efficiency of the maintenance and repair of weapons and military equipment. Armaments and military equipment, 2016, №2 (10), p. 43-48

8. Shatalov, O.E. Matuzko, B.P. Andrienko, A.M. Pashkovsky, V.V. Increasing survivability of the mechanized unit through the use of three-dimensional tactical diagrams. Military Technical Collection, 2011, № 1 (4), p. 112115.
9. Nor, P.I. Shchypanskyi, PV Gogonyants, S.Yu. Methods for assessing the technical level of the samplearms and military equipment. Weapons systems and military equipment, 2014, No. 3 (39), p. 49-54.

10. Zaluzhniy, R.M. Lavrinchuk, O.V. Sieriakov, I.I. Comparative analysis of the properties of the reliability and survivability of complex military systems. Weapons Systems and Military Equipment, 2009, No. 4 (20), p. 101104.

11. Chornyi, M.V. Stepanov, S.S. Matuzko, B.P. Information support for the assessment of the level of reliability of weapons and military equipment in use. Military Technical Collection, 2011, No.2 (5), p. 140-145.

12. Shyshanov, M.A. Melnyk, B.A. Kobyakov, L.I. Methodological basis for the development of programs for maintenance of armament and military equipment. Armaments and military equipment, 2016, №2 (10), p. 37-42.

13. Bisyk S.P. Approach to assess the mine resistance of armored combat vehicle hulls based on welded joints. Air Force Science and Technology of the Armed Forces of Ukraine, 2017, No.3 (28), p. 121-127.

14. Dachkovskyi V.O. Radchenko L.M. Methods of assessing the recoverability of weapons and military equipment. Scientific Journal Modern Information Technologies in Security and Defense, 2019, № 3 (36) p. 89-96.

15. Dachkovskyi V.O. Methods of substantiation of tactical and technical requirements for mobile weapons repair and military equipment. Social Development \& Security. 2019. №9 (6), p. 86-101.

16. Matsko, OY Tereshchenko, A.M. Kopashynskyi, S.A. Smirnov, V.O. Dachkovskiy, V.O. Prylypa, O.O. The main provisions of the military-technical policy of the state. Kyiv, NUOU, 2019, 352 p.

17. Dachkovskyi, V.O. Yaroshenko O.V. Kuznetsov, I.B. Ovcharenko, I.V. Fundamentals of Arms Restoration and Military Equipment. Kyiv, NUOU, 2019, 136 p. 